\title{
Analisis Deskriptif Eksplorasi Karir dan Kesesuaian Persepsi Karyawan Muda
}

\author{
Ulfa Maghfiroh, Yani Rahmawati, dan Bustanul Arifin Noer \\ Departemen Manajemen Bisnis, Fakultas Bisnis dan Manajemen Teknologi, Institut Teknologi Sepuluh \\ Nopember (ITS) \\ e-mail: ulfamaghfiroh96@gmail.com
}

\begin{abstract}
Abstrak-Mobilitas organisasi yang tinggi serta kurangnya eksplorasi selama tahap awal perkembangan karir dapat mempersulit individu dalam mendapatkan, mempertahankan atau bahkan meningkatkan jenjang karir yang sudah dipilih. Salah satu industri yang didominasi oleh karyawan muda adalah PT. Angkasa Pura I (Persero) Bandara Internasional Juanda. Akan tetapi, pola pengembangan karir pada perusahaan belum sepenuhnya sesuai dengan persepsi karyawannya. Oleh karena itu, penelitian ini bertujuan untuk mengetahui faktor-faktor eksplorasi karir dan kesesuaian persepsi karyawan muda. Desain penelitian adalah kuantitatif dan single-cross sectional. Pengambilan sampel menggunakan metode convenience sampling. Statistik deskriptif melalui perbandingan mean dan standard deviation digunakan sebagai teknik analisis data. Hasil analisis menunjukkan bahwa sebelum memasuki dunia kerja, karyawan muda pada perusahaan melakukan pencarian informasi mengenai peran kerja pada perusahaan. Selain itu, karyawan muda merasa memiliki ketrampilan dan kemampuan yang sesuai dengan kebutuhan perusahaan sehingga mampu menyelesaikan pekerjaan dengan baik.
\end{abstract}

Kata Kunci-Eksplorasi karir, Kesesuaian Persepsi, Karyawan Muda, Statistik Deskriptif.

\section{PENDAHULUAN}

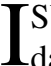
U tentang SDM terutama terkait pengelolaan karyawan dari generasi berbeda mendapat perhatian khusus dari manajer maupun peneliti. Satu hal yang menjadi perhatian adalah adanya perbedaan pada usia, karakteristik personal [1], jenjang karir dan nilai kerja [2]. Salah satu generasi yang relatif baru di pasar tenaga kerja adalah generasi milenial. Pada tahun 2016, komposisi karyawan muda pada PT. Angkasa Pura Airports didominasi oleh karyawan muda. Yaitu mereka yang masuk dalam golongan generasi milenial dengan kisaran usia 20 tahun sampai 37 tahun [3]. Survei kepuasan kerja pada perusahaan menunjukkan bahwa pola pengembangan karir pada perusahaan belum sepenuhnya sesuai dengan persepsi atau harapan karyawannya [4].

Saat ini, karyawan muda masih berada dalam tahap perkembangan. Tetapi kenyataannya beberapa dari karyawan muda tidak menyadari bahwa tahapan eksplorasi karir sangat penting untuk membantu menemukan pilihan karir yang tepat. Selain itu, individu yang melakukan eksplorasi terhadap kelebihan dan kekurangan yang dimiliki, secara tidak langsung juga melakukan ekplorasi lingkungan yang lebih baik [5]. Sehingga karaktersitik, minat dan kemampuan yang dimiliki akan sesuai dengan budaya organisasi dan tuntunan pekerjaan [6]. Hal ini juga didukung dengan penelitian dari Nie et al [7] bahwa terdapat hubungan signifikan antara ekplorasi karir terhadap kesesuaian persepsi yang di tengahi oleh nilai kerja. Oleh karena itu rumusan masalah yang akan diteliti adalah faktor apa saja yang mempengaruhi eksplorasi karir dan kesesuaian persepsi karyawan muda terhadap perusahaan.

\section{II.LANDASAN TEORI}

\section{A. Eksplorasi Karir}

Eksplorasi karir merupakan serangkaian aktivitas dalam meningkatkan pemahaman mengenai karakteristik personal terkait kelebihan dan kekurangan diri serta lingkungan atau jenis pekerjaan [8]. Proses eksplorasi mampu menghasilkan persepsi positif baik bagi pekerjaan maupun organisasi [7] sehingga membantu mempercepat proses pengembangan karir [8]. Terdapat 4 indikator yang digunakan untuk mengukur variabel eksplorasi karir. Keempat indikator tersebut mengadopsi dari penelitian yang dilakukan oleh Hurst dan Good [9], yaitu specific career, past experience, new work role, dan suitable career.

\section{B. Kesesuaian Persepsi}

Kesesuaian persepsi yang dimaksud dalam penelitian adalah kesesuaian persepsi individu (karyawan) dengan pekerjaan (person-job fit) maupun organisasi atau perusahaan tempat bekerja (person organization fit). Person-job fit merupakan kesesuaian antara pengetahuan, ketrampilan, dan kemampuan yang dimiliki individu dengan karakteristik pekerjaan [6]. Selanjutnya, Kristof et al [10] mendefinisikan person-organization fit sebagai kesesuaian antara nilai intrinsik individu dengan nilai-nilai organisasi yang berupa budaya dan struktur perusahaan. Variabel kesesuaian persesi diukur menggunakan 5 indikator yang mengadopsi penelitian Afsar et al [11], meliputi performance, job requirements, job personality, thing's valued by firm, firm's value and culture.

\section{Karyawan Muda}

Karyawan muda, yaitu mereka yang tergolong ke dalam generasi milenial adalah karyawan yang lahir di awal tahun 1980 hingga tahun 2000 [2]. Jika dibanding dengan generasi sebelumnya, karyawan generasi ini cenderung memiliki mobilitas organisasi tertinggi dalam jenjang karirnya [12]. Sehingga sulit bagi milenial untuk berkomitmen terhadap tujuan dan jenjang karir yang spesifik, jelas dan stabil [13]. Selain dikenal dengan perubahan dan perpindahan karir yang tinggi, milenial juga menginginkan variasi dalam penempatan kerja [14]. 


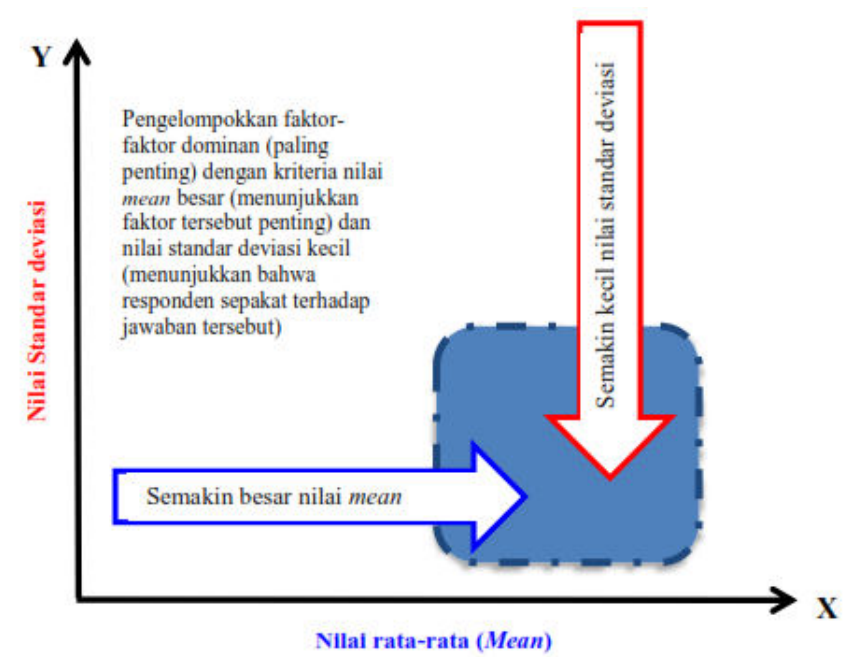

Gambar 1. Diagram perbandingan nilai mean dan standard deviation. Mengadopsi dari: Rahmawati et al [17].

\section{II.METODOLOGI PENELITIAN}

\section{A. Desain Penelitian}

Penelitian ini bersifat single cross-sectional, dimana hanya memberikan gambaran kondisi pada suatu populasi tertentu dengan pengambilan sampel dilakukan sekaligus dalam waktu yang sama [15]. Sedangkan pendekatan yang digunakan yaitu pendekatan kuantitatif dengan strategi studi kasus pada PT. Angkasa Pura I (Persero) Bandara Internasional Juanda. 102 karyawan pada perusahaan (usia 20 hingga 37 tahun) dipilih sebagai sampel penelitian dengan metode pengambilan sampel menggunakan convenience sampling. Data penelitian dikumpulkan melalui survei menggunakan kuesioner. Analisis statistik deskriptif dengan mengunakan perbandingan nilai mean dan standard deviation digunakan sebagai metode analisis data penelitian.

\section{B. Metode Analisis Data}

Hasil statistik deskriptif yang digunakan dalam penelitian adalah mean dan standard deviation serta scatter plot. Mean merupakan nilai rata-rata dari keseluruhan data pada variabel penelitian yang dapat menunjukkan karakteristik kelompok data penelitian dengan cara membandingkan keseluruhan nilai data dengan jumlah data. Sedangkan standard deviation merupakan nilai yang menunjukkan keheterogenan data dalam suatu penelitian. Selanjutnya, nilai mean dan standard deviation yang dihasilkan digambarkan dalam bentuk diagram scatter plot. Metode ini juga telah diaplikasikan dalam penelitian Fatimah et al [16]. lustrasi nilai mean dan standard deviation yang digambarkan melalui scatter plot disajikan dalam Gambar 1.

Diagram perbandingan antara nilai mean dan standard deviation mampu menggambarkan peringkat kepentingan suatu indikator ditinjau dari nilai mean dan standard deviation yang dihasilkan. Suatu indikator dianggap dominan apabila rata-rata yang dihasilkan bernilai besar. Artinya indikator tersebut dianggap penting oleh responden. Kriteria dominan lain adalah dengan nilai standar deviasi yang kecil, yang berarti bahwa mayoritas responden sepakat dengan jawaban tersebut. Sumbu X menunjukkan nilai ratarata dari masing-masing indikator. Sedangkan sumbu Y menyajikan nilai standar deviasi indikator penelitian.
Tabel 1.

Mean dan Standard Deviation

\begin{tabular}{|c|c|c|c|}
\hline Variabel & Indikator & Mean & St. Dev \\
\hline \multicolumn{4}{|c|}{ Eksplorasi Karir } \\
\hline CE1 & Specific career & 3,9412 & 0,7813 \\
\hline CE2 & Past experience & 4,1078 & 0,7566 \\
\hline CE3 & New work role & 3,9314 & 0,7481 \\
\hline CE4 & Suitable career & 3,5784 & 0,8137 \\
\hline Variabel & Indikator & Mean & St. Dev \\
\hline \multicolumn{4}{|c|}{ Kesesuaian Persepsi } \\
\hline FP1 & Performance & 3,9412 & 0,7151 \\
\hline FP2 & Job requirements & 3,7353 & 0,8435 \\
\hline FP3 & Job personality & 3,7451 & 0,7667 \\
\hline FP4 & Things valued by firm & 3,7647 & 0,7336 \\
\hline FP5 & Firm's value and culture & 3,902 & 0,8146 \\
\hline
\end{tabular}

\section{HASIL ANALISIS DATA DAN DISKUSI}

\section{A. Profil Responden}

Berdasarkan hasil analisis statistik deskriptif diketahui bahwa seluruh responden penelitian merupakan karyawan muda pada perusahaan dengan usia 20 tahun hingga 37 tahun, dengan proporsi responden terbanyak adalah perempuan, yaitu sejumlah 55 persen. 63 persen dari total responden telah menempuh pendidikan sarjana. Serta mayoritas merupakan staff perusahaan $(94 \%)$ yang berstatus sebagai pegawai swasta atau pegawai outsourcing (48\%). Sebagian besar responden mengaku pernah melakukan perpindahan tempat kerja sedikitnya 2 kali $(83 \%)$. Kemudian sebesar $56 \%$ responden mengaku sudah bergabung dengan perusahaan selama 3 hingga 8 tahun.

\section{B. Mean \& Standard Deviation}

Tabel 1 menunjukkan hasil analisis statistik deskriptif (mean dan standard deviation) dari kedua variabel penelitian (ekplorasi karir dan kesesuaian persepsi) beserta seluruh indikator yang digunakan.

Berdasarkan hasil analisis statistik deskriptif, diperoleh nilai mean tertinggi pada variabel ekplorasi karir dimiliki indikator past experience. Nilai tersebut menunjukkan bahwa rata-rata tingkat respon jawaban untuk indikator past experience berada pada skala 4. Artinya responden cenderung setuju bahwa sebelum memilih pekerjaan, karyawan muda mencari informasi mengenai kesesuaian pekerjaan saat ini dengan pekerjaan sebelumnya. Terbukti dari mayoritas responden mengaku memiliki latar belakang pendidikan dan pekerjaan yang sama dengan pekerjaan sebelumnya (pengalaman kerja). Selanjutnya jika ditinjau dari variabel kesesuaian persepsi, nilai rata-rata tertinggi berada pada indikator performance. Hasil ini mengindikasikan bahwa keahlian dan keterampilan yang dimiliki oleh karyawan sudah sesuai dengan kebutuhan perusahaan, sehingga mampu memberikan kinerja terbaik.

Hasil analisis statistik deskriptif juga menunjukkan bahwa tingkat varians data penelitian masih tergolong kecil. Hal tersebut terlihat dari nilai standard deviation yang dihasilkan pada variabel eksplorasi karir maupun kesesuaian persepsi cenderung kecil (tidak melebihi angka 1). 


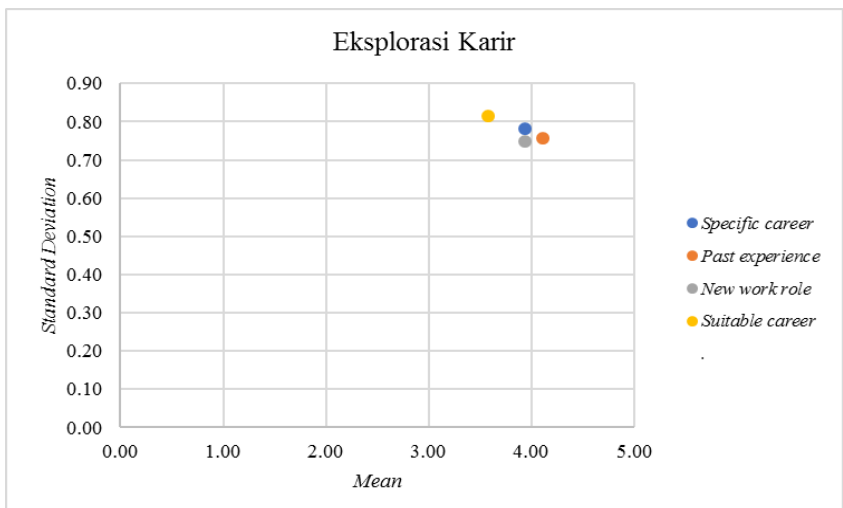

Gambar 2. Output Diagram Scatter variabel eksplorasi karir.

Pada variabel eksplorasi karir, indikator new work role memiliki nilai standar deviasi yang paling kecil. Hal tersebut berarti bahwa sebagian responden memiliki persepsi yang sama dalam hal pencarian informasi mengenai peran kerja pada sebuah jabatan atau pekerjaan. Sedangkan pada variabel kesesuaian persepsi, nilai standar deviasi terkecil dihasikan oleh indikator performance. Oleh karena itu, berdasarkan nilai standar deviasi dari seluruh indikator dapat dinyatakan bahwa data penelitian bersifat homogen. Hasil temuan ini juga didukung dengan strategi yang digunakan, yaitu studi kasus, dimana sampel diperoleh dalam satu jenis perusahaan yang sama. Sehingga memungkinkan tingkat respon jawaban responden yang homogen.

\section{Scatter Plot Mean dan Standard Deviation}

Rangkuman hasil analisis mean dan standard deviation dari kedua variabel penelitian (eksplorasi karir dan kesesuaian persepsi) ditunjukkan pada grafiik scatter plot. Output diagram scatter plot variabel eksplorasi karir disajikan dalam gambar 2.

Eksplorasi terkait pengalaman kerja masa lalu (past experience) maupun mengenai peran kerja pada sebuah perusahaan (new work role) memiliki nilai mean tertinggi jika dibanding indikator lain pada variabel eksplorasi karir. Selain itu, persepsi karyawan muda terhadap kedua indikator tersebut terbukti homogen, terlihat dengan nilai standard deviation yang dihasilkan relatif kecil. Jika dilakukan analisis secara lebih mendalam, indikator new work role merupakan indikator yang paling dominan dibanding indikator lain. Dibuktikkan dengan nilai rata-rata yang dihasilkan sebesar 3,93 dan nilai standar deviasi yang kecil, yaitu 0,74 . Hal tersebut mengindikasikan bahwa mayoritas karyawan muda pada perusahaan telah menerapkan ekplorasi mengenai peran kerja pada sebuah perusahaan sehingga tingkat respon jawaban yang dihasilkan relatif sama.

Gambar 3 menunjukkan output diagram scatter plot dari seluruh indikator variabel kesesuaian persepsi.

Berdasarkan analisis terhadap output diagram scatter variabel kesesuaian persepsi, dapat diketahui bahwa indikator performance memiliki nilai mean tertinggi. Artinya karyawan muda merasa memiliki ketrampilan dan kemampuan yang tepat sehingga mampu menyelesaikan tanggung jawab pekerjaan dengan baik. Tingkat varians jawaban responden dari indikator ini juga tergolong kecil. Hal tersebut dapat dilihat dari nilai standar deviasi yang dihasilkan sebesar 0,71 . Artinya, tingkat respon jawaban dari resonden bersifat homogen, dengan kata lain dapat dikatakan bahwa sebagian besar karyawan muda yang menjadi

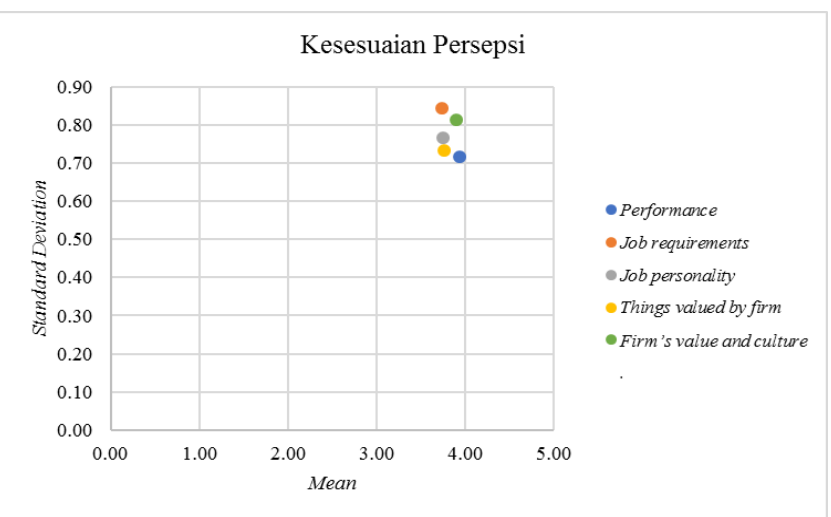

Gambar 3. Output Diagram Scatter variabel kesesuaian persepsi.

responden penelitian memiliki persepi yang sama mengenai indikator performance. Hasil analisis perbandingan antara nilai rata-rata dan standar deviasi dari keseluruhan indikator variabel kesesuaian persepsi mengidikasikan bahwa indikator performance merupakan indikator yang paling dominan jika dibanding dengan indikator lain.

\section{KESIMPULAN/RINGKASAN}

Berdasarkan penelitian yang telah dilakukan, ditemukan bahwa karyawan muda pada perusahaan sudah melakukan aktivitas eksplorasi terkait latar belakang atau pengalaman pekerjaan sebelumnya. Sehingga sebelum memasuki pekerjaan, mereka mencari informasi dan meningkatkan pemahaman mengenai peran kerja pada masing-masing jabatan di sebuah perusahaan. Hasil penelitian juga menunjukkan bahwa karyawan muda pada perusahaan merasa memiliki ketrampilan dan kemampuan yang sesuai dengan kebutuhan perusahaan sehingga mampu menghasilkan kinerja yang baik.

Temuan penelitian mendukung hasil penelitian dari Holland dan Cable \& DeRue. Individu yang melakukan eksplorasi terhadap kelebihan dan kekurangan yang dimiliki, secara tidak langsung juga melakukan ekplorasi mengenai lingkungan pekerjaan yang lebih baik. Sehingga keahlian dan kemampuan yang dimiliki akan sesuai dengan kebutuhan untuk dapat menyelesaikan tanggungjawab pekerjaan dengan baik.

Penelitian ini bersifat studi kasus pada satu jenis perusahaan dengan subjek penelitian karyawan muda (generasi milenial). Sehingga disarankan untuk penelitian selanjutnya menggunakan sampel responden yang berasal dari berbagai jenis perusahaan dengan tidak membatasi usia responden. Hal ini guna mengetahui perbedaan pola karir dari kelompok generasi yang berbeda.

\section{DAFTAR PUSTAKA}

[1] J. M. Twenge, "A review of the empirical evidence on generational differences in work attitude," J. Bus. Psychol., vol. 25, no. 2, pp. 201$210,2010$.

[2] L. Cennamo and D. Gardner, "Generational differences in work values, outcomes and person-organisation values fit," J. Manag. Psychol., vol. 23, no. 8, pp. 891-906, 2008.

[3] D. J. Cherrington, The Work Ethic: Working Values and Values That Work. New Jersey: Amacom Books, 1980.

[4] PT. Angkasa Pura Airports, "Membangun Kebanggaan Bangsa Melalui Percepatan Pembangunan Infrastuktur Bandara," Jakarta, 2016.

[5] J. L. Holland, Making Vocational Choices: A Theory of Vocational Personalities and Work Environments. Odessa, 1997. 
[6] D. M. Cable and D. S. DeRue, "The convergent and discriminant validity of subjective fit perceptions," J. Appl. Psychol., vol. 87, no. 5, pp. 875-884, 2002

[7] Z. L. T. Nie and H. Huang, "Huang, "Career exploration and fit perception of Chinese new generation employees: Moderating by work values," Nankai Bus. Rev. Int., vol. 3, no. 4, pp. 354-375, 2012.

[8] B. D. L, "Applying current theory and research in career exploration to practice," Career Dev. Q., vol. 41, pp. 174-184, 1992.

[9] J. L. Hurst and L. K. Good, "Generation Y and career choice: The impact of retail career perceptions, expectations and entitlement perceptions," Career Dev. Int., vol. 14, no. 6, pp. 570-593, 2009.

[10]B. A. L. Kristof, R. D. Zimmerman, and E. C. Johnson, "Consequences of individuals' fit at work: A meta-analysis of personjob, person-organization, person-group, and person-supervisor fit," Pers. Psychol., vol. 58, no. 2, pp. 281-342, 2005.

[11]B. Afsar, Y. Badir, and M. M. Khan, "Person-job fit, personorganization fit and innovative work behavior: The mediating role of innovation trus," J. High Technol. Manag. Res., vol. 26, no. 2, pp.
105-116, 2015.

[12]S. T. Lyons, L. Schweitzer, E. Ng, and L. Kuron, "Comparing apples to apples: A qualitative investigation of career mobility patterns acros four generations," Career Dev. Int., vol. 17, no. 4, pp. 333-357, 2012.

[13]D. C. Feldman, "The antecedents and consequences of early career indecision among young adults," Hum. Resour. Manag. Rev., vol. 13, pp. 499-531, 2003.

[14]L. C. Lancaster and D. Stillman, When Generations Collide. New York: Harper Collins, 2002.

[15]J. F. Hair, B. Babin, A. Money, and P. Samouel, Essentials of Business Research Methods. Denver: Leyh Publishing, 2003.

[16]Y. Rahmawati, C. Utomo, and F. Rahmawati, "Analsisis Deskriptif Penempatan Fabrikasi Pembesian terhadap Waktu Pelaksanaan Proyek Konstruksi," in Seminar Nasional Manajemen Teknologi XIII, 2011.

[17]N. Fatimah, N. Wessiani, and Y. Rahmawati, "Analisa Faktor-faktor Keberhasilan Penerapan Budaya Kaizen pada Perusahaan Manufaktu,' J. Sains dan Seni ITS, vol. 6, no. 1, pp. 47-49, 2017. 